\title{
Belt conveyor predictive diagnostics based on the monitoring of the drive motor electrical parameters
}

\author{
Dmitriy Anikanov ${ }^{1}$, Mikhail Kipervasser ${ }^{2,}$, Vadim Simakov ${ }^{2}$, and Dabin $\mathrm{Qi}^{3}$ \\ ${ }^{1}$ Sibshakhtostroy LLC, Novokuznetsk, 654005, Russia \\ ${ }^{2}$ Siberian State Industrial University, Novokuznetsk, 654007, Russia \\ ${ }^{3}$ University of Science and Technology Liaoning, Anshan, 14051, China
}

\begin{abstract}
The study focuses on the main malfunctions of the mechanical components transmitting rotational moment to belt conveyor pulley and the possibility of functional diagnostics of their technical condition. The results of electrical values of the drive were obtained for the modeled emergency modes of the conveyor operation in the Matlab Simulink programming environment.
\end{abstract}

\section{Introduction}

Transportation costs of the extracted minerals from the working face to the surface of the mine make up a significant part of the cost. This is also true for the products in the production of which belt conveyors are used. That is why the search for reserves increasing the efficiency of vehicles is of great importance.

The state of the equipment is considered normal if all its components and parts are in good working order, the parameters used to determine their condition do not approach the limit values, and the dynamics of changes in these parameters over a certain period allows a sufficiently long period of safe operation to be predicted.

Keeping conveyors in compliance with industrial safety requirements depends on the rational organization of maintenance and repair. In practice, overhaul periods are planned based on the calendar time of operation, and the running time, load intensity are not taken into account.

The existing system is not perfect and requires significant labor and financial costs. Major repairs are carried out without sufficient grounds and in a larger volume than it is required only on the basis of the service life. There is an opposite tendency - a technical device is repaired only after it has lost its functionality. Untimely replacement of worn parts increases the likelihood of emergency repairs.

Rollers, drum linings, cleaning systems, various seals, drums and of course the conveyor belt are conveyor wear parts. The resource of the components is determined by the performance of the equipment, as well as by the abrasiveness of the transportation

\footnotetext{
*Corresponding author: kipervasser2012@yandex.ru
} 
material, its bulk density, shock load in places of overload, etc. [1]. Mining conditions, such as high humidity, can help reduce the service life of belt wear parts.

In addition, the human factor affects the reduction of life cycle. Violation of operating conditions, improper adjustment of conveyor equipment, untimely replacement of failed components, ignoring the pre-emergency situations often reduce the life cycle of the entire conveyor system by several times. For example, if the belt is adjusted incorrectly, it starts tracking from side to side and gets torn against the metal structure of the conveyor line. In case of improper operation of cleaning systems, spills and buildups appear on the conveyor rollers and drums, which leads to an accelerated failure of the linings of the drums, bearing assemblies and the drums themselves and, as a result, accelerated wear of the conveyor belt.

A promising strategy for the maintenance and repair of transport belt equipment is maintenance based on the actual state, since the limiting states of structures and mechanisms are the result of a gradual accumulation of damage in parts, assemblies and elements. It is possible to reveal and eliminate the defects at the initial stage of development, ensuring the minimization of repair work, only by introduction of effective diagnostic methods [2].

\section{Methods of functional diagnostics of the belt conveyor technical condition}

Functional diagnostics is based on passive methods that register signals arising in the object itself under the influence of external factors (acoustic and electromagnetic emission, vibration, electrical and electromagnetic noise, thermal fields) [3].

During the operation of the belt conveyor, part of the energy transmitted from the electric motor to the tool of the unit is lost for various reasons: friction followed by heating, destruction followed by friction. All types of local diagnostics of an operating belt conveyor are based on the fact that they record and evaluate the magnitude and nature of energy losses in the mechanical components transmitting rotational moment to belt conveyor pulley.

It is possible to diagnose the failures of the mechanical components transmitting rotational moment given in table 1 for the subsequent predictive maintenance [4-6].

Table 1. Localizations and causes of malfunctions of mechanical components transmitting rotational torque in the belt conveyor.

\begin{tabular}{|l|l|}
\hline \multicolumn{1}{|c|}{ Malfunction, external manifestation } & \multicolumn{1}{c|}{ Probable cause } \\
\hline \multirow{2}{*}{ The drum, roller, roller, etc., do not rotate. } & Rolling bearing or labyrinth seal parts are destroyed. \\
\hline \multirow{4}{*}{$\begin{array}{l}\text { The belt tracks to the side at a certain } \\
\text { point. }\end{array}$} & $\begin{array}{l}\text { Skew of one or several rollers causing the belt to } \\
\text { move aside. }\end{array}$ \\
\cline { 2 - 3 } & Some of the rollers do not rotate. \\
\cline { 2 - 2 } & Carrying rollers are not horizontal. \\
\cline { 2 - 2 } & Misalignment of end and snub pulleys. \\
\hline \multirow{2}{*}{ The belt starts mistracking. } & Off-center loading of the belt. \\
\cline { 2 - 2 } & Insufficient rigidity of conveyor assemblies. \\
\hline \multirow{2}{*}{ Increased wear of the working belt cover. } & $\begin{array}{l}\text { Dirt accumulation of the bottom belt and seizure of } \\
\text { the return idler. }\end{array}$ \\
\hline
\end{tabular}




\begin{tabular}{|l|l|}
\hline \multirow{4}{*}{\begin{tabular}{l}
\multirow{4}{*}{$\begin{array}{l}\text { Increased wear of the non-working belt } \\
\text { cover. }\end{array}$} \\
\cline { 2 - 2 }
\end{tabular}} & $\begin{array}{l}\text { The lower part of the bearing structure is clogged and } \\
\text { the belt moves over the layer of material. }\end{array}$ \\
\cline { 2 - 2 } & $\begin{array}{l}\text { The tail pulley or the pulley of the conveyor } \\
\text { discharge carriage is piled with material. }\end{array}$ \\
\cline { 2 - 2 } & Seizure of the working rollers of the upper track. \\
\cline { 2 - 3 } $\begin{array}{l}\text { Groove cutting and cuts of the working } \\
\text { cover. }\end{array}$ & $\begin{array}{l}\text { The feeding tray seals are tightened against the belt } \\
\text { and are too hard. }\end{array}$ \\
\cline { 2 - 3 } & $\begin{array}{l}\text { The belt rubs against the metal parts of the feeding } \\
\text { tray. }\end{array}$ \\
\hline $\begin{array}{l}\text { Breakdown of the rubber cover and minor } \\
\text { breaks of the belt. }\end{array}$ & $\begin{array}{l}\text { Presence of foreign bodies in the transported material } \\
\text { (scrap, cutoff pieces, etc.) }\end{array}$ \\
\hline Transverse tears at the belt edge. & The belt bending up on the pulley or close to it. \\
\hline
\end{tabular}

The presented types of malfunctions are characterized by the influence of the process of their development on the change in the energy parameters of an electric machine, that is, on monitoring and analysis in real time: the rate of rise, the time of change (increase, decrease), the profile of the change, the frequency of changes in the energy parameters of the electric motor. The belt conveyor is considered as a specific object, which has a significant number of individual assemblies in its mechanical structure, united by elastic connection, and as a drive element, an asynchronous motor with a squirrel-cage rotor [6].

\section{Research of the joint electromechanical model of the belt conveyor mechanism in the Matlab Simulink environment}

Consideration of the mechanism as a complex of mechanical and electrical parts is the distinguishing characteristic of the proposed method of functional diagnostics.

The system of equations obtained in the process of building a dynamic model was solved in Matlab Simulink programming environment [7, 8]. A trial version of Matlab.ru was used for this purpose - Version: 7.9.0.529 (R2009b), 32-bit (win32). A functional diagram was drawn up (fig. 1) based on blocks presented in Matlab Simulink library [9-11].

Scope blocks were used for visual control of the parameters. The supply voltage was monitored by bock Scope No. 1, the current was monitored by block Scope No. 2. The electric motor torque and the load torque of the belt conveyor mechanical part was controlled by block Scope No. 3 .

Simulation of emergency operation was carried out using blocks Step No. $4-9$ distributed over the mechanical part of the belt conveyor simulation model. In the process of modeling of conveyor elements failure modes, the following cases were considered:

1) The mode of the mechanism operation with a rated load, followed by seizure of one, two and three rollers of the belt conveyor carrying part.

The obtained results of modeling the investigated mechanism of the belt conveyor are presented in the form of a graph in fig. 2. 


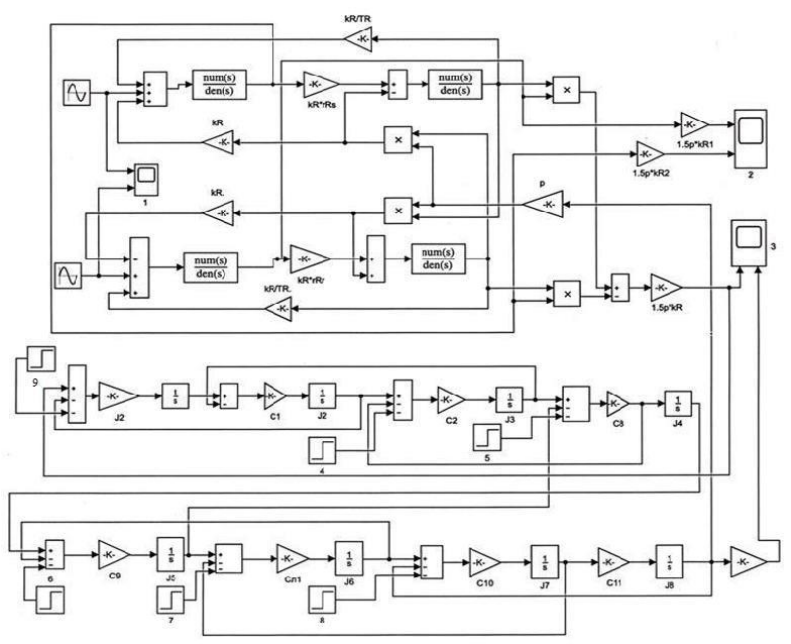

Fig. 1. Block diagram of the belt conveyor electromechanical system.

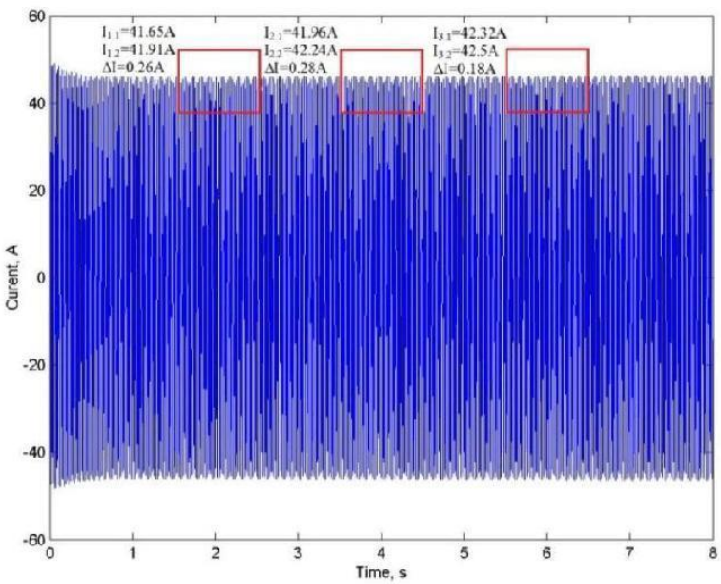

Fig. 2. The stator current behavior of induction motor simulated in Matlab Simulink environment. I1.1, I2.1, I3.1 are stator current before the emergency torque application; I1.2, I2.2, I3.2 - stator current after emergency torque application.

The operating mode of the belt conveyor is realized through additional torque application. The point of additional torque application in the considered model is block (Step No. 4).

From the graph shown in fig. 2, it can be seen that the modeled seizure of the carrying rollers is accompanied by the change in the controlled value of the stator current. When simulating the seizure mode of carrying roller of the load-carrying part, the stator current increases by $0.26 \mathrm{~A}$, when two carrying rollers are sized - the stator current increases by $0.28 \mathrm{~A}$, when three carrying rollers are sized - the stator current increases by $0.18 \mathrm{~A}$. The transient period is $0.2 \mathrm{~s}$, for the first simulated mode $0.45 \mathrm{~s}$ and in the second case $-0.45 \mathrm{~s}$ and $0.62 \mathrm{~s}$ with three sized rollers.

2) Clogging of the receiving hopper. The real process is accompanied by an excess amount of transported material in the receiving hopper. The obtained results of modeling the investigated mechanism of the belt conveyor are shown in fig. 3 . 


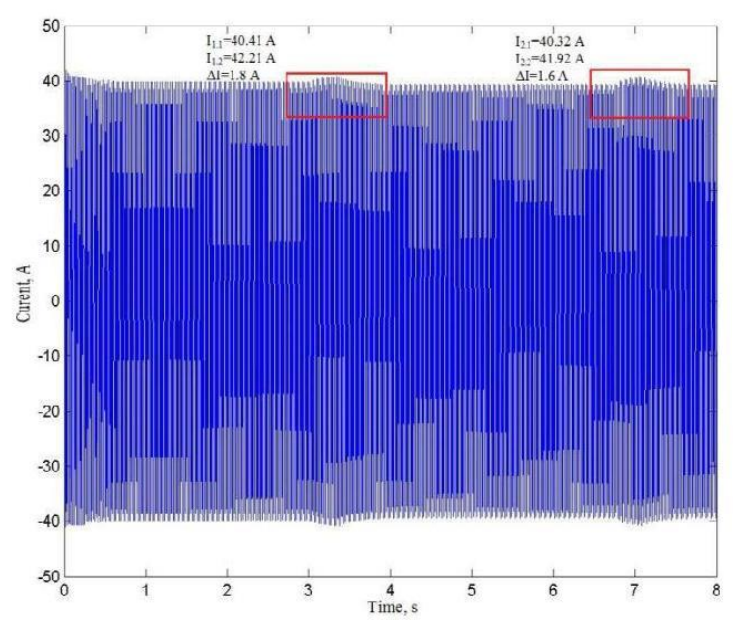

Fig 3. The stator current behavior of induction motor simulated in Matlab Simulink environment during clogging of the receiving hopper.

The graph in fig. 3 shows the magnitude of the change in stator current. Point of the additional torque application in the considered block model (Step No. 8). The estimated value of the applied torque is $89 \mathrm{~N}^{*} \mathrm{~m}$. It can be seen from the graph that the modeled mode of the receiving hopper clogging is accompanied by the jump in the stator current, in the first case by $1.8 \mathrm{~A}$. The time of the transient period is $1.69 \mathrm{~s}$.

3) Seizure of the gear reducer. The causes of this mode are the ingress of foreign bodies between the gear teeth, a critical misalignment, chipping of the gear teeth. The obtained results of modeling the investigated belt conveyor mechanism are presented in the form of a variance graph of the stator current in fig. 4. The point of the additional torque application in the considered model block (Step \# 9). The estimated values of the applied torque is taken as $140 \mathrm{~N}^{*} \mathrm{~m}$.

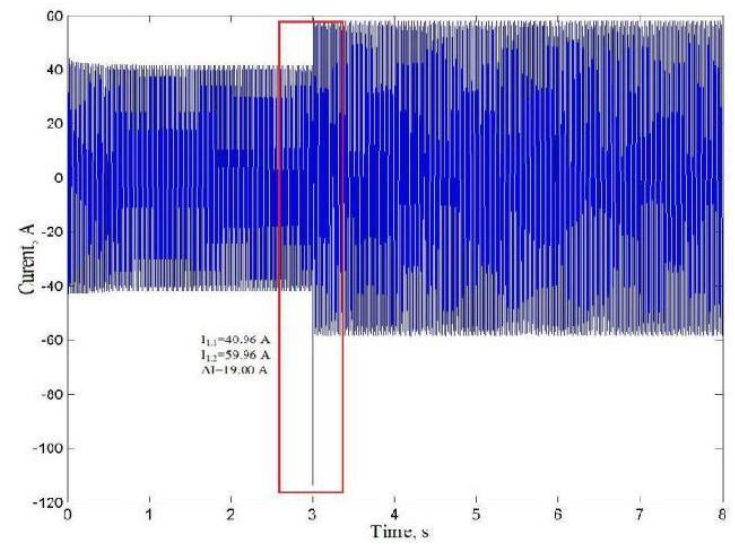

Fig. 4. The stator current behavior of induction motor simulated in Matlab Simulink environment in the mode of gear reducer jamming.

From the graph shown in fig. 4, it can be seen that the simulated mode of gear reducer jamming is accompanied by an increase in the stator current by 19 A. At the same time, there is a decrease in the angular velocity to negative values. The transient period is $1.68 \mathrm{~s}$.

4) Cutting off the coupling pins. The modeling results of the investigated mechanism of the belt conveyor are shown in fig. 5 . 


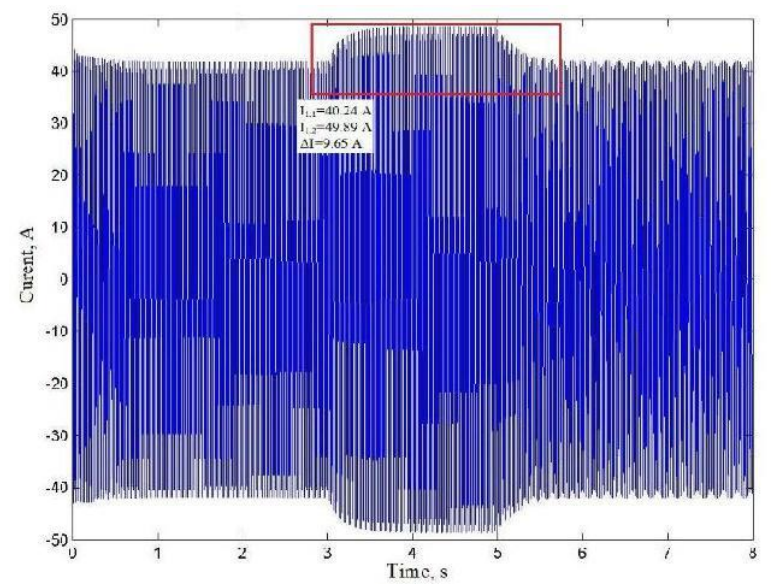

Fig. 5. The stator current behavior of induction motor simulated in Matlab Simulink environment in the mode of cutting the coupling pins.

A similar result of operating the mechanism occurs for a number of reasons: poorquality components, excess of the permissible torque on the gear reducer shaft or drum, as well as improper installation of the connecting pins shows the amount of change in stator current. Point of additional torque application in the considered block model (Step No. 9). The estimated value of the applied torque is taken as $96 \mathrm{~N} * \mathrm{~m}$.

From the graph (fig. 5) it can be seen that the simulated mode of cutting coupling pins is accompanied by an increase in the stator current by $9.65 \mathrm{~A}$. At the same time, there is a decrease in the angular velocity to negative values. The transient period is $1.53 \mathrm{~s}$, and the induction motor returns to normal with $5 \mathrm{~s}$ simulation. From the graphs in fig. 2-5 it can be seen that the stator currents of the induction motor contain the necessary information for diagnosing the technical condition of the belt conveyor mechanism. Malfunction, damage to elements, units in the mechanical components transmitting rotational moment to belt conveyor pulley affects the power consumption from the network by the drive motor which leads to fluctuations in stator currents. The period, frequency and form of oscillations depend on the specific type of malfunction that occurs in the mechanical part of the belt conveyor.

\section{Conclusion}

The study of the combined electromechanical model of the belt conveyor mechanism in the Matlab Simulink environment showed that changes in the mechanical torque, due to the mechanical failure of the components transmitting rotational torque to belt conveyor pulley, lead to changes in the electrical parameters of the drive induction motor of the belt conveyor (when diagnosing, the envelopes of instantaneous currents values for each phase of the stator are determined).

\section{References}

1. A. Kuchumova, Extrction Industry, 6(24) (2020)

2. Yu.I. Kropotov, Young Scientist, 23(103) (2015) 
3. V.V. Nosov, Diagnostics of machines and equipment (Lan, $\mathrm{SPb}, 2012)$

4. V.A. Dyakov, et al, Belt onveyors in the mining industry (Nedra, Moscow, 1982)

5. A.I. Basov, Mechanical equipment of concentration factories and plants of heavy nonferrous metals (Metallurgy, Moscow, 2008).

6. Yu.A. Epifantsev, Mechanical equipment for ore dressing (Mech. Eng., Moscow, 2004)

7. A.N. Saveliev, M.V. Kipervasser, D.S. Anikanov, Izv. Vuzov. Fer. Met., 12 (2015)

8. E.V. Pugachev, M.V. Kipervasser, D.S. Anikanov, Bull. of KuzSTU, 3(97) (2013)

9. V.B. Teryokhin, Modeling of electric drive systems in Simulink (TPU, Tomsk, 2010)

10. V.P. Dyakonov, SIMULINK 4. Special reference book (Peter, SPb, 2002)

11. V.P. Dyakonov, MATLAB 6/5 SP1/7 + Simulin 5/6. Basics of application (SOLONPress, Moscow, 2005) 